\title{
Immunological mechanisms in the pathogenesis of cerebral palsy
}

\author{
Yevgen Lisovskyy, Kenzhe Kussainova, Meiram Shakenov, Natalya Lisovska \\ «Republican Children's Rehabilitation Centre» JSC, Science and Education Department, Astana, Kazakhstan
}

\begin{abstract}
The cerebral palsy is highly actual issue of pediatrics, causing significant neurological disability. Though the great progress in the neuroscience has been recently achieved, the pathogenesis of cerebral palsyis still poorly understood. In this work we reviewed available experimental and clinical data concerning the role of immunocompetent cells in pathogenesis of cerebral palsy. Maintaining of homeostasis in nervous tissue and its transformation in case of periventricular leukomalacia were analyzed. The reviewed data demonstrate involvement of immune regulatory cells in the formation of nervous tissue imbalance and chronicity of inborn brain damage. The supported opinion, that periventricular leukomalacia is not a static phenomenon, but developing process, encourages us optimism about possibility of its correction. The further study of changes of the nervous and immune systems in cerebral palsy will contribute to creating fundamentally new directions of the specific therapy and individual schemes of rehabilitation.
\end{abstract}

Key words: cerebral palsy - tissue homeostasis - periventricular leukomalacia - immune regulation - apoptosis.

J Clin Med Kaz 2016; 1(39):6-11

Автор для корреспонденции: Лисовский Евгений Владимирович, АО «Республиканский детский реабилитационный центр». Адрес: 010000, проспект Туран 36, Астана, Казахстан. Тел.: +7(702) 584-17-41, 511-543; 13-60. E-mail: lisovski67@gmail.com.

\section{БАЛАЛАР ЦЕРЕБРАЛДЫ САЛ АУРУЫНЫҢ ЭТИОПАТОГЕНЕЗІНДЕГІ ИММУНОЛОГИЯЛЫҚ МЕХАНИЗМДЕРІ Лисовский Е.В., Құсаинова К.К., Шакенов М.Ж., Лисовская Н.Ю. \\ «Республикалық балаларды оңалту орталығы» АҚ, Ғылым мен білім бөлімі, Астана, Қазақстан}

\section{Тұжырымдама}

Балалар церебралды сал ауруы балалардың мүгедектігін туғызатындықтан өзекті мәселе болып табылады. Неврология ғылымының дамуының жетістіктеріне қарамастан, церебралды сал ауруының патогенезі әлі толық түсінікті емес. Бұл жұмыста біз жүйке ұлпасындағы қалыпты және перивентрикулярды лейкомаляция жағдайындағы тіндік гомеостазды реттеудегі иммундық жасушалардың рөліне қатысты тәжірибелік және клиникалық деректерді талдадық. Осы шолуда ұсынылған деректер ишемиялық ми жарақатының және оның кейіннен созылмалы тіндік үйлесімсіздіктің қалыптасуында иммундық жасушалар қатысуын куәландырады. Позициялық көзқарас бойынша перивентрикулярды лейкомаляция статистикалық феномен болып табылмайды, бірақ үдеріс уақытында дамытатын, оның түзету мүмкіндігіне қатысты оптимизмді орнатады. Церебралды сал ауруы кезіндегі жүйке және иммундық жүйелердің өзгерістерін одан әрі зерттеу нақты терапияның және оңалтудың жеке сызбаларының жаңа бағыттарын қалыптастырады. апоптоз

Маңызды сөздер: балалардың церебралды сал ауруы - тіндік гомеостаз - перивентрикулярды лейкомаляция - иммундық реттеу -

\section{ИММУНОЛОГИЧЕСКИЕ МЕХАНИЗМЫ В ЭТИОПАТОГЕНЕЗЕ ДЕТСКОГО ЦЕРЕБРАЛЬНОГО ПАРАЛИЧА}

Лисовский Е.В., Кусаинова К.К., Шакенов М.Ж., Лисовская Н.Ю.

$\mathrm{AO}$ «Республиканский детский реабилитационный центр», Отдел науки и образования, Астана, Казахстан

\section{Резюме}

Детский церебральный паралич является актуальной проблемой, поскольку вызывает тяжелую детскую инвалидность. Несмотря на прогресс, достигнутый неврологической наукой, этиопатогенез церебрального паралича до сих пор до конца не ясен. В этой работе мы проанализировали экспериментальные и клинические данные касающиеся роли иммунокомпетентных клеток в регуляции тканевого гомеостаза в нервной ткани в норме и в случае перивентрикулярной лейкомаляции. Данные, приведенные в обзоре, свидетельствуют о вовлечении иммунокомпетентных клеток в фрормировании тканевого дисбаланса при ишемическом повреждении мозга и последующей его хронизации. Позиционируемая точка зрения о том, что перивентрикулярная лейкомаляция не является статическим феноменом, а скорее развивающимся во времени процессом, вселяет оптимизм в отношении возможности ее коррекции. Дальнейшее изучение изменений в нервной и иммунной системах при церебральном параличе будет способствовать формированию новых направлений специфической терапии и индивидуальных схем реабилитации.

Ключевые слова: детский церебральный паралич - тканевой гомеостаз - перивентрикулярная лейкомаляция - иммунорегуляция апоптоз.

\section{Введение}

Детский церебральный паралич (ДЦП) - одно из распространенных заболеваний, приводящих к тяжелой инвалидности. В структуре детской инвалидности церебральный паралич составляет по данным различных авторов от 30 до $70 \%[1,2]$. Заболеваемость ДЦП в мире достигает 2-2,5 случая на 1000 новорожденных [3]. Дефиниция ДЦП сделана Исполнительным комитетом Международного семинара,проходившего 11-13июля2004годавBethesda(США): ДЦП определяется как «группа перманентных нарушений развития моторики и позы, вызывающих ограничение активности, которые относятся к не прогрессирующим 
расстройствам, произошедшим в развивающемся мозге плода или младенца» [4]. По другому существующему определению «ДЦП - собирательный термин, объединяющий группу неврологических расстройств, возникших в результате недоразвития или повреждения мозга в раннем онтогенезе» [2]. Несмотря на значительную пластичность мозга ребенка, тяжелое расстройство нейронального развития и нарушение процессов нормальной миелинизации в результате повреждения мозга в неонатальном периоде [5] приводит к постоянному моторному и когнитивному дефициту с широкой вариабельностью клинической картины.

В настоящее время в мировой медицине уделяется большое внимание реабилитационным программам для детей с церебральным параличом и ранней диагностике органического поражения ЦНС, поскольку именно раннее начало восстановительного лечения дает больше шансов получить хорошие результаты [6]. Однако недостаточная во многих случаях эффективность реабилитации приводит к постепенному снижению мотивации к реабилитации ДЦП в целом [2]. Реабилитационные программы, по сути, являются симптоматическими и разрабатываются на основании существующих у пациента синдромов. Патогенетической терапии ДЦП, как таковой, не существует. Кроме того, существующий взгляд на патогенез нервных дегенераций, к которым можно отнести и детский церебральный паралич, заключающийся в том, что гибель нервных клеток значительно превышает их репарационный потенциал, предопределяет определенный пессимизм при прогнозировании результатов реабилитации [7]. В тоже время известно, что наиболее успешной является терапия и реабилитация, основанная на этиопатогенетическом подходе. Учитывая успехи нейробиологической науки, современные достижения молекулярной биологии и генетики, подходы к терапии и реабилитации детей с церебральным параличом должны трансформироваться с учетом новых знаний $[8,9]$.

Не вызывает сомнения, что в основе клинических проявлений ДЦП лежит патология развития головного мозга [10,11]. В тоже время, остается много проблемных моментов и неразрешенных вопросов. Так, не существует однозначного объяснения тому факту, что у одних детей, с выявленной различными видами визуализации патологией головного мозга выражена клиника ДЦП, а у других детей с такой же картиной патологии головного мозга клиника отсутствует или она незначительна. Почему в тех случаях, когда при проведении нейросонографии и ЭЭГ диагностируются функциональные и морфологические изменения и у пациента удается добиться клинического улучшения, патоморфологические изменения в головном мозге не претерпевают обратного развития? Почему у $30 \%$ детей с ДЦП доступными методами нейровизуализации не выявляется патологических изменений в головном мозге? Ответы на эти и другие вопросы, касающиеся этиопатогенеза и клинического течения церебрального паралича, необходимы для формирования этиопатогенетической стратегии терапии и реабилитации, ставящей конечной целью улучшение курабельности этой сложной патологии у детей.

\section{Современная концепция патогенеза ДЦП}

Современная концепция патогенеза церебрального паралича у детей рассматривает два основных взаимосвязанных механизма. С одной стороны, это нарушение тканевого гомеостаза в нервной ткани, связанное с нарушением кровоснабжения и регуляции апоптотической гибели клеток $[12,13]$. А с другой стороны, - иммунологические нарушения, отражающие формирование аутореактивности в отношении патологически измененной нервной ткани $[5,14,15]$. В связи с этим, можно выделить несколько наиболее важных и перспективных современных направлений исследования механизмов патогенеза ДЦП и разработки подходов к его лечению.

Исследованиями последних лет показано, что активность нейронов и нервной системы в целом гомеостатически регулируется $[16,17,18]$. Поддержание физиологических переменных при помощи гомеостатических механизмов - фундаментальное свойство всех живых организмов. Необходимо помнить, что интеграция функциональной активности клеток различных тканей в единое целое, а также управление процессами структурной перестройки ткани, происходят под влиянием регуляторных систем. В настоящее время существует концепция, согласно которой взаимодействие иммунной, нервной и эндокринной систем поддерживают в организме информационное равновесие, а система крово- и лимфообращения формирует каналы связи и обеспечивает возможность обмена информацией [19]. На тканевом уровне процесс обмена информацией поддерживается постоянным синтезом различных, коротко живущих молекул (хемокинов, молекул межклеточной адгезии), обеспечивающих синхронизацию процессов, протекающих под контролем регуляторных систем [18]. И, если основные механизмы передачи сигналов регуляторных систем в общих чертах ясны, то разъяснение механизмов согласованного взаимодействия различных мессенджеров межклеточной коммуникации, которые обеспечивают адекватную реакцию клеток на изменение условий внешней среды, - является наименее изученной стороной проблемы [17]. Проблема изучения межклеточных коммуникаций представляется еще более сложной, если учесть, что активную роль в формировании тканевого ансамбля играет внеклеточный матрикс [20]. Причем, внеклеточный матрикс является не пассивной, а активной средой, которая вносит свой вклад в процессы межклеточной коммуникации, обеспечивает процессы миграции клеток. Помимо коллагеновых и эластиновых волокон в формировании внеклеточного матрикса участвуют адгезивные гликопротеиды, цитокины, гормоны, факторы роста [21,22].

Таким образом, регуляция тканевого гомеостаза представляет собой сложную иерархическую систему с множеством известных факторов и с частью неизученных компонентов, а улучшение информированности о деталях отстает от концептуального понимания проблемы [17]. Возможный выход из сложившейся ситуации лежит в поиске интегральных показателей, отражающих состояние ткани и потенциальное направление ее развития в определенный момент времени. Логично искать показатели, характеризующие работу сложно организованной системы поведения ткани, среди параметров регуляторных систем иммунной, нервной и эндокринной, работающих в тесной взаимосвязи друг с другом. С этих позиций, хотелось бы вкратце остановиться на функциональной анатомии нервной системы и нейрогенезе.

\section{Функциональная анатомия нервной системы и нейрогенез}

Отсутствие обычного лимфатического дренирования мозга, низкий уровень экспрессии молекул Major Histocompatibility Complex (главный комплекс 
гистосовместимости, МНС) на клетках мозга, наличие гемато-энцефалического барьера предполагают взгляд на головной мозг как иммунологически привилегированный орган. Тем не менее, иммунные клетки представлены в нервной системе, и различные формы иммунного ответа могут возникать и развиваться при соответствующих условиях [23]. Предполагается, что формирование любого типа иммунологической реакции в головном мозге является нежелательным и всегда проявляется тем или иным патологическим процессом [24,25]. Гемато-энцефалический барьер рассматривается в настоящее время не как фильтр, $\mathrm{a}$, скорее, как избирательность потока веществ, ионов и информационных молекул, обусловленная тесными межклеточными связями между нейронами, глиальными клетками и эндотелием капилляров мозга [26,27]. Наиболее интереснойпредставляетсяфункцияастроцитовимикроглии, исследования которой привели к предположению о том, что эти клетки могут опосредовать индукцию специфических признаков барьерного фенотипа в эндотелии капилляров мозга. Кроме того, установлена обратная индукция, проявляющаяся в том, что эндотелий мозга влияет на рост и дифференцировку ассоциированных астроцитов. Культивируемые эндотелиальные клетки мозга и астроциты экспессируют функциональные рецепторы для большого числа агентов, действующих как нейротрансмиттеры и модуляторы в мозге [28]. Эти экспериментальные данные подтверждают, что существует физиологическая возможность передачи сигналов между клетками в нейроваскулярной единице, включающей помимо нейронов и эндотелия сосудов, микроглию и олигодендроциты [10]. Кроме того, сигнальное взаимодействие между микроглией, астроцитами и нейронами также может быть крайне важным при различной патологии мозга [26].

Астроциты и эндотелиальные клетки мозга рассматриваются как контролеры нейронального гомеостаза, поэтому их дисфункция оказывает существенные эффекты на нейрофизиологическом уровне. Наиболее полной является, на наш взгляд, концепция регуляции тканевого гомеостаза в нервной ткани, включающая, наряду с нейроваскулярной единицей, клетки иммунной системы и внеклеточный матрикс [29,30]. Согласно этой концепции, ЦНС способна отвечать на действие патогенов (токсины, травма, дегенеративные стимулы) развитием сложного каскада процессов на клеточном и тканевом уровнях, условно называемым нейровоспалением. Эта цепь реакций реализуется в результате согласованного действия иммуноцитов (к которым относится и микроглия, и астроциты), клеток эндотелия и нейронов, образующими в комплексе так называемую иммунорегуляторную 3ону[27]. Иммунорегуляторная зона, по сути, является периферическим компартментом иммунной системы, то есть тем звеном, где происходит взаимодействие эффекторных (регуляторных) иммуноцитов с тканевыми структурами, передача информации и формирование тканевого гомеостаза.

Для проверки этой концепции необходимо более глубокое и тщательное изучение сложных и изменяющихся паттернов нейрогенеза при различных заболеваниях нервной системы. Нейрональные стволовые и прогениторные клетки, содержащиеся в центральной нервной системе взрослых организмов в определенных количествах, сохраняют способность генерировать новые нейроны в определенных областях головного мозга [31]. Такой нейрогенез в постнатальном мозге является важнейшей формой нейропластичности, необходимой для его функционирования [32,33]. Нейропластичность удивительная способность мозга изменять свои основные структуры и функции; некоторые из этих изменений кратковременны, но очень ярко выражены, другие менее заметны, но долговременны [34]. Гены, механизмы развития мозга и нейропластичность взаимосвязано играют ведущую роль в формировании состояния мозга [35]. С точки зрения очень широкого понятия нейропластичности, которое подразумевает адаптацию нервной системы в норме и при патологии на всех уровнях, от системного до синаптического, можно интерпретировать практически все события, происходящие при функционировании мозга. Нарушение нейрогенеза считается ключевым патогенетическим механизмом различных заболеваний мозга [36,37]. Вопрос о том, каким образом участвует вызванный различными повреждениями нейрогенез в восстановлении мозга, остается в целом открытым. В последние годы активно развивается «не нейроцентричный» взгляд на различную патологию нервной системы, предполагающий участие и других клеточных элементов мозга в этиологии заболеваний $[29,34]$

Нейрогенное воспаление является, по-видимому, формой нарушения гомеостаза, которое стимулирует повышение метаболической активности и информационных потребностей, позволяющих реализовать свойство нейропластичности [25]. В основе нейрогенного воспаления лежат нарушения функционирования нейроглиальных сетей и связанные с ними нарушения гематоэнцефалического барьера. При этом классические медиаторы воспаления, цитокины и простагландины, выполняют в мозге нейромодуляторные функции. Внеклеточный матрикс регулирует важные процессы развития, роста и функционирования нейронов [30]. Изучение состава внеклеточного матрикса с целью его ремоделирования представляет одно из важнейших новых направлений, в результатеразвития которого могут быть разработаны новые подходы к патогенетической терапии церебрального паралича у детей.

Перивентрикулярная лейкомаляция является одним из наиболее постоянных морфологических признаков ДЦП [11,38,39]. По имеющимся литературным данным этот процесс инициируется во внутриутробном периоде и продолжается в течение всего периода болезни. Существует мнение о процессуальности патологических изменений в перивентрикулярных структурах мозга - возникая под действием гипоксии во внутриутробном периоде, они продолжаются в течение всего периода детства [38].То есть, перивентрикулярная лейкомаляция рассматривается не как статический, а как текущий, возможно, иммунопатологический процесс тканевой деградации на фоне аутосенсибилизации организма собственными мозговыми антигенами, препятствующий эффективности терапии заболевания. Аутореактивную природу заболевания подтверждает тот факт, что у больных ДЦП частота выявления аутоантител к изученным нейроспецифическим белкам в крови больных увеличена в 2,3 раза, а содержание циркулирующих иммунных комплексов достоверно превышает уровень у здоро ᄀвых лиц в 1,7 раза; при этом, количество и функциональная активность Т-лимфоцитов, 
особенно CD8+ лимфоцитов значительно уменьшается [14].

Современные данные о физиологической регуляции тканевого гомеостаза в нервной ткани, как упоминалось ранее, предполагают тесное взаимодействие между нервной, эндокринной и иммунной системами. Иммунная система в ЦНС представлена тремя морфологически и функционально отличающимися клеточными элементами: лимфоидные клетки спинномозговой жидкости, нелимфоидные клетки нервной ткани (микроглия, астроциты, олигодендроциты), клетки эндотелия мозговых сосуᄀдов. Кроме того, активированные Т-лимфоциты могут проникать в ЦНС через гемато-энцефалический барьер для обеспечения функции иммунологического надзора. Цитокины (интерфероны, интерлейкины, TNF и др.) как медиаторы иммунной системы участвуют в процессах взаимодействия между иммунными и нервными клетками, в том числе - в механизмах повреждения вещества мозга и убыли нейронов [12]. Нейроглия поддерживает стабильную внутреннюю среду для нервной ткани, обеспечивая тканевой гомеостаз и функционирование нервных клеток [40,41,42]. Известно, что значительная часть нейроцитов (от 20 до $80 \%$ ) погибает путем программированной физиологической гибели, апоптоза, в ходе гистогенеза. Биологический смысл запрограммированной гибели клеток глии заключается, с учетом уже известных фактов о физиологическом смысле апоптоза, в передаче генетической информации нейроцитам, необходимой для их дифференцировки и приобретения специализации [43]. Клетки микроглии имеют определенные свойства иммунокомпетентных клеток: они способны к миграции (амебоидному движению), фагоцитозу продуктов нервной ткани в очагах некроза и посторонних частиц, участвуют в транспорте этих продуктов в околососудистые и подпаутинные пространства [40]. На клетках глии экспрессирован CD4-маркер Т-хелперов, который имеется на лимфоцитах, некоторых моноцитах - этот трансмембранный гликопротеин участвует в распознавании антигенов, ассоциированных с молекулами II класса гистосовместимости. МНС -большая область генома, которая отвечает за координированное действие различных клеток иммунной системы и играет важную роль в формировании иммунного ответа [44]. Кроме того, нейрональные стволовые клетки также имеют фенотип астроглии (GFAP+ клетки) и они чаще всего локализованы в субэпендимальном слое желудочков и перивентрикулярной зоне мозга [16]. Это еще раз подтверждает важность этой зоны мозга в процессах гистогенеза нервной ткани в постнатальном периоде. Исходя из приведенного выше, больные ДЦП представляют собой особую группу пациентов с сочетанным поражением нервной и иммунной систем.

Ведущую роль в поддержании клеточного гомеостаза тканей и органов взрослого организма играет апоптоз универсальныймеханизмгенетическизапрограммированной клеточной гибели, тесно сопряженный с процессом фагоцитоза апоптотических телец, необходимым для дифференцировки высокоспециализированных клеток, в том числе в нервной ткани. Массивная гибель клеток происходит в период завершения миграции, пролиферации и начала тканеспецифической дифференцировки нервных элементов $[43,45]$. Особенно напряженно эти процессы протекают в эмбриогенезе, в процессе становления нервной ткани; в постнатальном периоде эти процессы протекают менее интенсивно, но являются не менее важными, поскольку выступают базовымидля формирования полноценной нервной системы $[33,36]$. Что касается участия процесса апоптоза в патологии нервной системы, то выраженный апоптоз имеет место при ишемических повреждениях мозга [12].Одним из способов элиминации Т-клеток из очагов нейровоспаления также является апоптоз. В развитии церебральных дегенераций, к которым относят и детский церебральный паралич, апоптоз играет особую роль [13]. Учитывая роль процессов дифференцировки и апоптоза нейроцитов в процессе онтогенеза нервной системы, и их важность для функционирования мозга в постнатальном периоде, а именно для обеспечения его нейропластичности, состояние апоптотической программы в организме необходимо учитывать при разработке программ лечения и реабилитации пациентов с патологией головного мозга.

В настоящее время разрабатываются терапевтические стратегии, основывающиеся на ингибировании или активации апоптотического вида гибели клеток. Терапию апоптоза целесообразно проводить по трем направлениям: подавлять процесс апоптоза при его избыточности; устранять факторы, подавляющие апоптоз, при его недостаточности; использовать индукторы дифференцировки. В раннем постнатальном периоде индуктором апоптоза является ограничение притока афферентной информации, которая служит источником трофических стимулов как для развивающейся, так и для уже зрелой нервной системы. Это подтверждается тем фактом, чтоприток сенсорной информации является организатором процессов созревания и трофического обеспечения нервной системы $[46,47,48]$. То есть, непрерывный приток информации выступает в качестве главного условия существования и развития нервной системы. Принимая во внимание этот факт, становится понятной роль и эффективность физических факторов реабилитации в процессе этиопатогенетической коррекции у детей с церебральным параличом. Важным фактором, препятствующим избыточному апоптозу и некрозу клеток, является усиление нейротрофического обеспечения мозга $[21,49,50]$, что подтверждает важность нейротрофических препаратов в медикаментозной реабилитации пациентов с церебральными заболеваниями [7,15].

\section{Выводы}

Церебральный паралич у детей, несмотря на многообразие клинических форм, с позиций иммунологической регуляции тканевого гомеостаза можно рассматривать как возникшее перинатально и длительно персистирующее нарушение структуры нервной ткани, приводящее к стойким функциональным нарушениям. Однако, учитывая свойство нейропластичности, наиболее развитое в молодом возрасте, эти изменения нервной ткани могут быть обратимыми, что вселяет надежду на эффективность этиотропного лечения. Идентификация морфологических и биохимических маркеров апоптоза и показателей, характеризующих иммунорегуляцию тканевого гомеостаза в нервной ткани, должна в перспективе способствовать более глубокому пониманию механизмов этиопатогенеза заболеваний, улучшению диагностики и созданию новых направлений этиопатогенетической терапии и разработке индивидуальных схем реабилитации больных ДЦП. 


\section{Литература}

1. Galym A.G., Dostaeva B.S., Berdykenova A.Zh., Usembaeva R.B., Bestonova L.T. Analiz zabolevaemosti i profilaktika detskogo cerebral'nogo paralicha (Analysis of prevalence and prevention of children's cerebral palsy), Vestnik KAZNMU, 2012 (sen), pp. 6-9.

2. Semenova K.A.Vosstanovitel'noe lechenie detej s perinatal'nym porazheniem nervnoj sistemy i detskim cerebral'nym paralichom (Rehabilitation of children with perinatal impact of nervous system andchildren's cerebral palsy), M.: Zakoniporjadok, 2007, $616 \mathrm{p}$.

3. Nelson K.B. Can we prevent cerebral palsy? N Engl J Med,2003, 349, pp.1765-1769.

4. Rosenbaum P, Paneth N, Leviton A, Goldstein M, Bax M, Damiano D, Dan B, Jacobsson B. A report: the definition and classification of cerebral palsy April 2006, Dev Med Child NeurolSuppl, 2007, Feb, 109, pp.8-14.

5. Ortega, Sterling B., et al. «Perinatal chronic hypoxia induces cortical inflammation, hypomyelination, and peripheral myelinspecific T cell autoreactivity. Journal of leukocyte biology, 2016, No.99.1, pp. 21-29.

6. Bulekbaeva Sh.A., Sultanova G.M., Dzhanieva T.S. Sovremennye metody v kompleksnoj reabilitacii detskogo cerebral'nogo paralicha (Contemporary methods in the complex rehabilitation of children's cerebral palsy), Rukovodstvo dlja vrachej, Astana, 2008, 98 p.

7. Ismagilov M.F., Isanova V.A. Opyt ispol'zovanija nejrodinamicheskih metodov reabilitacii v vosstanovlenii dvigatel'nyh funkcij (Experience of application of neurodynamic methods in rehabilitation of movement function), Nevrologicheski jzhurnal, 2008, №3, pp.105-109.

8. Gajnetdinova D.D., Gajsina L.Z. Fenomen nestabil'nosti kletochnogo genoma v patogeneze detskogo cerebral'nogo paralicha (Phenomenon of instability of cellular genome in pathogenesis of children's cerebral palsy), Zhurna lnevrologii I psihiatriiim. S.S. Korsakova, 2012, №10, pp. 49-51.

9. O’Callaghan M.E., MacLennan A.H., Haan E.A. The genomic basis of cerebral palsy, Hum. Genet, 2009, №1, pp. 49-72.

10. Morgun A.V., Kuvacheva N.V., Taranushenko T.E., Hilazheva E.D., Malinovskaja N.A., GorinaJa.V., Pozhilenkova E.A., Frolova O.V., Salmina A.B. Sovremennye predstavlenija o patogeneze perinatal'nogo ishemicheskogo povrezhdenija kletok nejrovaskuljarnoj edinicy golovnogo mozga: molekuly-misheni dlja nejroprotekcii (Contemporary insight in pathogenesis of ischemic perinatal impairment of cells of the neurovascular unit of brain: molecular targets for neuroprotection), Vestnik RAMN, 2013, 12, pp. 26-35.

11. Kaur C., Ling E.A. Periventricular white matter damage in the hypoxic neonatal brain: role of microglial cells, Prog. Neurobiol,2009, №4, pp. 264-280.

12. Morgun A.V., Ovcharenko N.V., Taranushenko T.E. Markery apoptoza I nejrospecificheskie belki v diagnostike perinatal'nyh porazhenij central'noj nervnoj sistemy u novorozhdennyh detej (Markers of apoptosis and neurospecific proteins in the diagnostic of perinatal impact of central nervous system in newborns), Sibirskoemed. Obozrenie, 2013, №3 (81), pp. 3-11.

13. Smirnov I.E., Rovenskaja Ju.V., Zajniddinova R.S., Kucherenko A.G. Dinamikafaktorovapoptozapriperinatal'nyhporazhenijah central'nojnervnojsistemy u detejpervogogodazhizni (Dynamics of the factors of apoptosis during perinatal impacts of central nervous system in children at the first year of life), Rossijskij pediatricheskij zhurnal, 2011, №6, pp. 4-9.

14. Semenov A.S., Skal'nyj A.V. Immunopatologicheskie I patohimicheskie aspekty patogeneza perinatal'nogo porazhenija mozga (detskij cerebral'nyj paralich, alkogol'nyj sindrom ploda) (Immunopathological and pathochemical aspects of the pathogenesis of perinatal impact of the brain (children's cerebral palsy, alcohol syndrome of fetus), SPb.: Nauka, 2009, 368 p.

15. Serkina E.V., Gromova O.A., Torshin I.Ju., Sotnikova N.Ju., Nikonov A.A. Cerebrolizin oblegchaet sostojanie bol'nyh s perinatal'nym porazheniem CNS cherez moduljaciju autoimmuniteta I antioksidantnuj uzashhitu (Cerebrolysin improve state of patients with perinatal impact of CNS through the modulation of autoimmunity and antioxidant defense), Zhurnal nevrologii I psihiatriiim. S.S. Korsakova, 2008, №11, p. 62-66.

16. Zhivolupov S.A. Samarcev I.N., Syroezhkin F.A. Sovremennaja koncepcija nejroplastichnosti (teoreticheskie aspekty I prakticheskaja znachimost') (Contemporary conception of neuroplasticity or etical aspects and practical importance), Zhurn. nevrologiiipsihiatriiim. S.S. Korsakova, 2013, №10, pp. 102-108.

17. ShilovV.N. Molekuljarnye mehanizmy strukturnogo gomeostaza (Molecular mechanisms of structural homeostasis), M.: «Intersignal», 2006, 288 p.

18. SenovillaL, GalluzziL, ZitvogelL, KroemerG.Immunosurveillance as a regulator of tissue homeostasis, Trends in immunology, 2013, 34;10, pp.471-481.

19. Babaeva A.G., Gevorkjan N.M., Zotikov E.A. Rol' limfocitov v operativnom izmenenii programmy razvitija tkanej (The role of lymphocytes in operative changing of the program of tissue development), M.: RAMN, 2009, $107 \mathrm{p}$.

20. Fujioka H., Dairyo Y., Yasunaga K., Emoto K. Neural Functions of Matrix Metalloproteinases: Plasticity, Neurogenesis, and Disease, Biochemistry Research International, Vol. 2012. 2012, Article ID 789083, 8 p.

21. Soleman S., Filippov M.A., Dityatev A., Fawcett J.V. Targeting the neural extracellular matrix in neurological disoders, Neuroscience, 2013, 253, pp.194-213.

22. VestweberD. Adhesion and signaling molecules controlling the transmigration of leukocytes through endothelium, Immunol. Rev, 2007, 218, pp.178-196.

23. Haitov R.M., Pinegin B.V., Jarilin A.A. Rukovodstvo po klinicheskoj immunologii. Diagnostika zabolevanij immunnoj sistemy: rukovodstvo dlja vrachej (Manual of clinical immunology. Diagnostic of diseases of immune system: manual for phisiciance), M: GJeOTAR-Media, 2009, 352 p.

24. Vezzani A., Friedman A., Dingledine R.J. The role of inflammation in epileptogenesis, Neuropharmacology, 2013, 69, pp.16-24.

25. Xanthos D.N. Sandkuhler J. Neurogenic neuroinflammation: inflammatory CNS reactions in response to neuronal activity, Nat. Rev. Neuroscience, 2014, 15 (1), pp.43-53. 
26. Kuvacheva N.V., Salmina A.B., KomlevaJu.K., Malinovskaja N.A., Morgun A.V., Pozhilenkova E.A., Zamaj G.S., Jauzina N.A., Petrova M.M. Pronicaemost' gemato-jencefalicheskogo bar'era v norme, pri narushenii razvitija golovnogo mozga I nejrodegeneracii (Penetration of hematoencephalic barrier in normal case and in case of deviations of brain development and neurodegeneration), Zhurnal nevrologii I psihiatriiim. S.S. Korsakova, 2013, 113(4), pp.80-85.

27. StranfordS.,Ruddle N. Follicular dendritic cells, conduits, lymphatic vessels, and high endothelial venules in tertiary lymphoid organs: parallels with lymph node stroma, Front. Immunol, 2012 (30, nov), p.3389.

28. Abbott J.N., Rönnbäck L., Hansson E. Astrocyte-endothelial interactions at the blood-brain barrier, Nature Reviews Neuroscience, 2006 (January), №7, pp. 41-53.

29. Janigro D., Walker M.C. What non-neuronal mechanisms should be studied to understand epileptic seizures? Adv. Exp. Med. Biol, 2014, 813, pp.253-264.

30. Wojcik-Stanaszek L., GregorA.,Zalewska T. Regulation of neurogenesis by extracellular matrix and integrins, ActaNeurobiolExp, 2011, 71, pp.103-112.

31. Repin V.S., Rzhaninova A.A., Shamenkov D.A. Jembrional'nye stvolovye kletki (Embryonic stem cells), Fundamental'naja biologija I medicina, M: ReMeTjeksju, 2002, 225 p.

32. Braun S.M., Jessberger S. Adult neurogenesis and its role in neuropsychiatric disease, brain repare and normal brain function, Neuropathol. Appl. Neurobiol, 2014, 40(1), pp. 3-12.

33. Taupin P. Adult neurogenesis and neuroplasticity, RestorNeurolNeurosci, 2006, 24(1), pp. 9-15.

34. Guljaeva N.V., Aniol V.A. Epilepsija I nejroplastichnost': sovremennye koncepcii I napravlenija razvitija issledovanij, v knige «Sovremennaja jepileplogija: problem ireshenija» (Epilepsy and neuroplasticity: contemporary conceptions and directions of the investigations, in book "Contemporary epileptology: problems and decisions") pod red. Guseva E.I., Geht A.B., 2015, M: OOO «Buki-Vedi» 520 p. pp. 207-216.

35. Simpkins C.A., Simpkins A.M. Neuroplasticity and Neurogenesis: Changing Moment-by-Moment, Neuroscience for Clinicians, 2013, 11 (Sep), pp. 165-174.

36. Hsieh J.,Eisch A. Epigenetics, hippocampal neurogenesis, and neuropsychiatric disorders: Unraveling the genome to understand the mind, Neurobiology of Disease, 2010, Vol. 39, Issue 1, July, p. 73-84.

37. Strat Y.L., Ramoz N. Gorwood P. The Role of Genes Involved in Neuroplasticity and Neurogenesis in the Observation of a Gene-Environment Interaction (GxE) in Schizophrenia, Current Molecular Medicine, 2009, 9, №4, pp. 1-13.

38. Ajzatulina D.V. Process y svobodnoradikal'nogo okislenija pri nestabil'nosti genoma u bol'nyh detskim cerebral'nym paralichom s periventrikuljarnoj lejkomaljaciej (Processes of free radical oxidation at the genome instability in patients with children's cerebral palsy and periventricular leucomalacia), Avtoref. Dis. ... kand. med. nauk, Kazan', 2009,24 p.

39. Vlasjuk V.V. Periventrikuljarnaja lejkoma ljacija u detej (Periventricular leucomalacia in children), SPb. GelikonPljus, 2009, $172 \mathrm{P}$.

40. Obuhov D.K., Pushhina E.V. Radial'naja glija - kak I stochniknov yh nejronov v postnatal'nom razvitii CNS (Radial glial cells as the origin of new neurons in postnatal development of CNS), Mezhd. zhurn. jeksper. obr., 2011, №6, pp. 10-11.

41. Pushhina E.V. Rol' radial'noj glii v pre- I postnatal'nom gistogeneze nervnoj sistemy pozvonochnyh(The role of radial glial cells in the pre- and postnatal histogenesis of nervous system of chords), Aktual'nye problem gumanitarnyh I estestvennyh nauk, 2010, №1, pp. 12-17.

42. Skvorcov I.A., Ermolenko N.A. Razvitie nervnoj sistemy u detej v norme I patologii (Development of neural system in children in normal case and in case of pathology), M. -MED press-inform, 2003, $367 \mathrm{p}$.

43. Green D., Reed J. Apoptosis. Physiology and Pathology, Cambridge University Press, 2011, 438 p.

44. Zhiznevskij B. L. Klinicheskoe znachenie antigenov kompleksa NLA pri detskom cerebral'nom paraliche (Clinical importance of antigens of HLA complex for children's cerebral palsy), Avtoref. Dis. ... kand. med. nauk. M, 1994, 22 p.

45. Choi C., Benveniste E. Fas ligand/Fas system in the brain: regulator of immune and apoptotic responses, Brain Res Brain Res Rev, 2004, 44, 1, pp. 65-81.

46. Ismagilov M.F., Isanova V.A. Korteksin v kompleksnoj reabilitacii bol'nyh detskim cerebral'nym paralichom (Kortexin in complex rehabilitation of patients with children’s cerebral palsy), Nevrologicheskij zhurnal, 2008, №4, pp.125-127.

47. Ekusheva E.V., Damulin I.V. Rehabilitation after stroke: the role of neuroplasticity and sensorimotor integration, Zh.Nevrol. Psikhiatr. imS.S.Korsakova, 2013, 113, 12Pt2, pp.35-41.

48. Tahayori B., Port N.L., Koceja D.M. The inflow of sensory information for the control of standing is graded and bidirectional, Exp Brain Res, 2012, 218, 1, pp.111-118.

49. Penionzhkevich D.Ju., Gorbunov F.E. Novye tehnologii nejrometabolicheskoj terapii pri cerebrovaskuljarnyh zabolevanijah (New technologies of neurometabolic therapy for cerebrovascular diseases), Zhurn. Nevrologiii psihiatriiim. S.S. Korsakova, 2009, №7, pp. 19-22.

50. Park D.H., Eve D.J., Chung Y.G. Regenerative medicine for neurological disorders, The Scientific.World. J, 2010, 10, pp. 470489. 